\title{
Differential Expression Screening of Defense Related Genes in Dormant Buds of Cold-Treated Grapevines
}

\author{
Seon Ae Kim ${ }^{1}$, Soon-Young Ahn', Jae Hyun Han ${ }^{1}$, Seung Heui $\mathrm{Kim}^{2}$, Jung Ho Noh${ }^{2}$, and Hae Keun Yun ${ }^{1 *}$ \\ ${ }^{1}$ Department of Horticultural Science, Yeungnam University, Gyeongsan 712-749, Korea \\ ${ }^{2}$ National Institute of Horticultural and Herbal Science, RDA, Suwon 441-706, Korea
}

\begin{abstract}
Grape (Vitis spp.), which is an important economic fruit crop worldwide, is the fourth most common fruit produced in Korea. Low temperature is one of the most important environmental factors that affect the successful cultivation of grapes. To screen for specific expression of abiotic stress-related genes against cold treatment in 'Campbell Early' and 'Muscat Bailey A' grapevines, the expression of various defense-related genes was investigated by real-time PCR and semi-quantitative RT-PCR. Among 67 genes analyzed by real-time PCR and RT-PCR, 43 and 10 were found to be up-regulated, while 4 and 37 were down-regulated in low temperature treated 'Campbell Early' and 'Muscat Baily A' grapevines, respectively. Genes encoding cold induced protein $(C I P)$, lipoxygenase $(L O X)$, glutathione $S$-transferase $(G S T)$, polygalacturonase-inhibiting protein $(P G I P)$, and cold acclimation specific protein $(C A S 15 A)$ were up-regulated, while those encoding cinnamyl alcohol dehydrogenase $2(C A D 2)$ and cold acclimation protein (WCS120) were down-regulated by low temperature treatment in both 'Campbell Early' and 'Muscat Bailey A'. These changes in gene expression showed that defense response-related genes for cold acclimation were induced and wheat cold-specific gene decreased in grapevines. Among tested genes, the transcript levels of $C L P$, cell wall protein $(C W), T I P, T L P$, and WRKY transcription factor 10 (WRKY10) increased considerably in response to low temperature in 'Campbell Early' grapevine. These findings suggest that differentially expressed genes could be utilized as candidates for useful genetic resources and molecular markers after additional confirmation in various grapevine cultivars treated with low temperature in breeding programs for grapes with cold-tolerance.
\end{abstract}

Keywords Cold stress, Freezing tolerance, Grape breeding, Vitis

\section{INTRODUCTION}

Grapes (Vitis spp.) are an important economic fruit crop cultivated globally; however, they often encounter cold stresses due to changes in environmental conditions. Accordingly, cold damage caused by extremely low temperature is a serious problem associated with grape production. As grapevines are deciduous perennial plants, they acquire tolerance to freezing in advance of annual freezes to enable to overwinter in canes and buds (Sreekantan et al. 2010).

Crops respond and adapt to cold stress by changing their patterns of gene expression (Yang et al. 2011). Many cold responsive genes and their gene products are considered to function in cold tolerance at transcriptional and biochemical levels (Sanghera et al. 2011).
Consistent with the expected effects of a calcium signal, cold-acclimation causes phosphorylation of a number of proteins (Momroy and Dhindsa 1995; Monroy et al. 1993). When plants are exposed to cold or chilling stress at temperatures of 0 to $-15^{\circ} \mathrm{C}$, they attempt to maintain homeostasis to acquire freezing tolerance, which involves extensive reprogramming of gene expression and metabolism and changes in structural components (Hughes and Dunn 1990). Both cold acclimation and chilling tolerance are involved in an array of biochemical, molecular and metabolic processes (Cook et al. 2004; Kotak et al. 2007; Larkindale et al. 2005; Thomashow 1999; Zhu et al. 2007). Therefore, understanding the molecular basis of cold stress responses in plants will help us develop cold-tolerant grape cultivars. Recently, damage by extremely low temperatures during

Received Mar 3, 2013; Revised Mar 23, 2013; Accepted Mar 25, 2013; Published March 31, 2013

*Corresponding author Hae Keun Yun, haekeun@ynu.ac.kr, Tel: +82-53-810-2942, Fax: +82-53-810-4659 
winter has become a serious problem in viticulture in Korea (Ahn et al. 2012); therefore, programs for selection of new grape cultivars tolerant to coldness are required. This study was conducted to obtain a better understanding of the general differential expression and provide a basis for further analysis. The specific goals of this study were to detect differentially expressed genes in grapevines following low temperature treatment and provide useful genetic resources for breeding programs of cold-tolerant grapes.

\section{MATERIALS AND METHODS}

\section{Plant materials and cold treatment}

One-year old vine cane with latent buds of 'Campbell Early'(moderately tolerant to cold stress) and 'Muscat Bailey A' (MBA, sensitive to cold stress) grapevines were harvested in February 2011, cut to small cuttings with 1 bud, and used for cold treatment. Cold treatment of buds was carried out at $-20^{\circ} \mathrm{C}$ in the dark for $0,6,12$, and $24 \mathrm{~h}$, respectively. The buds treated with coldness were collected at the indicated times, frozen in liquid nitrogen and stored at $-80^{\circ} \mathrm{C}$ until further use. Untreated buds were collected for use as a control $(0 \mathrm{~h})$.

\section{RNA isolation and cDNA synthesis}

Total RNA was extracted from grapevine buds using a modified version of the method described by Yang et al. (2008). Fifty buds from each treatment were used for RNA extraction. The yield and quality of total RNA were measured based on the absorbance at 230, 260, and $280 \mathrm{~nm}$ using a NanoDrop spectrophotometer (ND-1000, Technologies Inc., USA). First-strand cDNA was synthesized from the total RNA (500 ng) using a PrimeScript ${ }^{\mathrm{TM}} 1^{\text {st }}$ strand cDNA synthesis kit (Takara Bio Inc., Japan) and subsequently used as a template for PCR.

\section{Real-time PCR and semi-quantitative RT-PCR analysis}

The various defense-related genes showing changes of their expression against foreign stresses were selected to analyze their expression patterns to cold treatment in grapevines. The expression of selected genes was tested by real-time PCR and semi-quantitative RT-PCR using gene specific primer pairs (Table 1). Real-time PCR was performed on a $1000^{\mathrm{TM}}$ Thermal Cycler (BioRad, USA) using SYBR Premix Ex (TaKaRa Bio Inc., Japan) as the fluorescent dye. Amplification was conducted by subjecting the samples to one cycle at $95^{\circ} \mathrm{C}$ for $5 \mathrm{~min}, 40$ cycles of $95^{\circ} \mathrm{C}$ for $20 \mathrm{~s}$, $60^{\circ} \mathrm{C}$ for $30 \mathrm{~s}$ and $72^{\circ} \mathrm{C}$ for $30 \mathrm{~s}$. All reactions were performed in triplicate to ensure consistency of the results. Each real-time assay was tested to ensure that there was onlya single PCR product using a high resolution melting profiling technique. Real-time PCR results were analyzed as previously described (Wu et al. 2010). Semi-quantitative RT-PCR was performed by subjecting the samples to the following conditions: initial denaturation at $94^{\circ} \mathrm{C}$ for 5 min, followed by 30 cycles at $94^{\circ} \mathrm{C}$ for $45 \mathrm{sec}, 55^{\circ} \mathrm{C}$ for 45 sec, and $72^{\circ} \mathrm{C}$ for $1 \mathrm{~min}$ and then final extension for $7 \mathrm{~min}$ at $72^{\circ} \mathrm{C}$. The actin gene primers were used as an internal control. The PCR products were identified by $1.5 \%(\mathrm{~W} / \mathrm{V})$ agarose gel electrophoresis with $0.5 \mathrm{X}$ TBE running buffer. After taking the gel picture using a transilluminator (UVP, CA, USA), the expression levels were measured by analysis of the images using a public domain image analysis system (NIH ImageJ, NIH Image, Bethesda, USA).

\section{REULTS AND DISCUSSION}

The differential expression of genes was evaluated by real-time PCR and semi-quantitative RT-PCR with primer pairs (Table 1). The expression patterns of 67 genes involved in defense responses to abiotic stress were evaluated following low temperature treatment of 'Campbell Early' and 'MBA' grapevines using quantitative real-time PCR (Fig. 1, 2, and 3). Among the tested genes, 43 and 10 were up-regulated, while 4 and 37 genes were down-regulated by low temperature treatment in 'Campbell Early' and 'MBA', respectively.

Among the tested genes, the transcript levels of coldtolerance such as $\mathrm{CBF}$ like transcription factor $(C B F 1)$, ATP dependent $\mathrm{Clp}$ protease $(C l p P)$, cell wall protein $(C W)$, sirtuin $(S I R T)$, tonoplast intrinsic protein $(T I P)$, pathogenesis-related (PR) genes such as chitinase $(C L P), \beta$ -1,3-glucanase $(G l u)$, and thaumatin $(T L P)$, lipoxygenase 
Table 1. Sequences of gene specific primers used for real-time PCR analysis.

\begin{tabular}{|c|c|c|c|}
\hline Name & Primer sequences & Name & Primer sequences \\
\hline$\beta$-amylase (BMYl) & 5'-TCCACTCCCAGAATGGGTTAGA-3' & Late embryogenesis abundant protein ( $L E A)$ & 5'-CTGACGTGGCAGAAGCAATG-3' \\
\hline (XM0022745762) & 5'-TTTTAAAACCCGCTCCTTGTCA-3' & (NM129540.4) & 5'-TCGGACGCCATTTTCTTAGC-3' \\
\hline Ascorbate peroxidase $(A P X)$ & 5'-GGTCCGTTTGGGACAATGAA-3' & Lipid transfer protein $(L T P)$ & 5'TGGAAGCAACCATAACATGTGG-3' \\
\hline (EU280159.1) & 5'-CGGAAATTGCTCCTTGATCG-3' & (LOC100256718) & 5'-TTGAGGCTCTTAATCCCACTGC-3' \\
\hline ATP dependent $\mathrm{Clp}$ protease $(\mathrm{Clp} P)$ & 5'-TCACCCGACCAAATTGAAGC-3' & Lipoxygenase $(L O X)$ & 5'-AACCTTGCGAGGTAATGGTCAA-3' \\
\hline (XM00227683.1) & 5'-AACTCCCCGATCCTCAGAGC-3' & (XM_002285538.2) & 5'-TACCACCAAGTACCGGTCGAGT-3' \\
\hline $\mathrm{CBF}$ like transcription factor $(C B F 1)$ & 5'-GGGTTTGCTCCTTACTCCACCT-3' & Leucine-rich repeats $(L R R)$ & 5'-GCCGATTTGGATCTCTCTCTGA-3' \\
\hline (AY390372.1) & 5'-CATCATCCCAGCTGAATCCTTT-3' & (XM002285517.2) & 5'-GTATGCTCACCGCCGAGTTAAT-3' \\
\hline Cell wall protein $(\mathrm{CW})$ & 5'-TTGACAAGAAGCAGCCTGAGTG-3' & Manganese superoxide dismutase $(M n-S O D)$ & 5'-GTTCATGAGGGAGGTGGTGAAC-3' \\
\hline (XM_002277798.1) & 5'-TGCTGCCATCATAGGGAGTGTA-3' & (EU280161.1) & 5'-TCTATAGCCCAACCCAGTGAGC-3' \\
\hline Chalcone isomerase $(\mathrm{CHI})$ & 5'-TACACTGACGCAGAAGCCAAAG-3' & Mitogen-activated protein kinase (MAPK) & 5'-CCCTCCTGATGAGGATTCATTG-3' \\
\hline (XM002282072.2) & 5'-GACCCATCTTTGGAGAAGCTCA-3' & (AY395740.1) & 5'-ATTCGAACTCCATCCCTGTTGA-3' \\
\hline Chalcone synthesis $(\mathrm{CHS})$ & 5'-AGTTCAAGCGCATGTGTGAAAA-3' & MYB Transcripton factor $(M Y B)$ & 5'-CACAAAGTCCATCTCCCCAAAC-3' \\
\hline (EF192464.1) & 5'-CTTCAACCACCACCATGTCTTG-3' & (XM_002265978.1) & 5'-TCTCCATTTCCTCCTGAACTCG-3' \\
\hline Chitinase-like protein $(C L P)$ & 5'-CCGATTTCTTCCAGACCTACCA-3' & O-methyltransferase (MT) & 5'-CCAGACACCATCCACAACCA-3' \\
\hline (XM002269123.1) & 5'-CAAATCCGTGAGGCTGGTAAAC-3' & (JF808016.1) & 5'-GCAGCAAGGAAGCCAGAATG-3' \\
\hline Cinnarmyl alcohol dehydrogenase2 (CAD2) & 5'-GGGCGTCCTCTCTCCATTTC-3' & Osmotin like protein $(O S M)$ & 5'-ACTGCAACTTCGATGCGTCA-3' \\
\hline (NM127743.3) & 5'-TCCCCAATGGTTCTTGATGG-3' & (Y10992.1) & 5'-TGCGAATTCGGCTAAGGTGT-3' \\
\hline Cold acclimation protein WCS120 (WCS120) & 5'-CATGGACACGCTGGAGTGAT-3' & Pathogen related protein $4 \mathrm{a}(P R 4 a)$ & 5'-GCTGCCCAGAGCGCTAGTAA-3' \\
\hline$(\mathrm{M} 93342.2)$ & 5'-TGTCCCAGTGCCAGTCGTT-3' & $(\mathrm{AF} 061329.1)$ & 5'-TCCCAAGTGGAGCAGTAGGC-3' \\
\hline Cold acclimation-specific (CAS15A) & 5'-CATGCTGGTGACCACAAAGG-3' & Pathogen related protein $6(P R 6)$ & 5'-CTGGTGGGAGTTCAGGGAGA-3' \\
\hline (L12462.1) & 5'-TTCCCCATGGTATCCCTCCT-3' & $(\mathrm{AY} 156047.1)$ & 5'-CCAAACACGGACCCTAGTGC-3' \\
\hline Cold induced protein $(C I P)$ & 5'AAGGGTGCAAAGCAAAGAGATG-3' & Phenylalanine ammonia lyase $(P A L)$ & 5'-TGAACAATGGCGAAAGTGAGAA-3' \\
\hline (XM002283501.1) & 5'-ATGCTGATGATCCATGGGAAGT-3' & $(X 75967.1)$ & 5'-TCTCTTGCGCTCTCAACCTCTT-3' \\
\hline Cold regulated protein $15 \mathrm{a}(C O R 15 a)$ & 5'-ACCTCAACGAGGCCACAAAG-3' & Polygalacturonase-inhibiting protein $(P G I P)$ & 5'-GTCTTACTCGCCACTCGTCCAT-3' \\
\hline (NM_129815.4) & 5'-CCGCAGCTTTCTCAGCTTCT-3' & $(\mathrm{AF} 305093.1)$ & 5'-GTTGGGATTCCACGAAGCTAGA-3' \\
\hline Cytochrome B5 (CYB5) & 5'-AGAGGAGCATCCTGGTGGTG-3' & Proline rich protein2 (PRP2) & 5'-CCACCTAAGATTAAACCGCGACT-3' \\
\hline (XM002283578.1) & 5'-GCATGCTGTGGCCCAAAA-3' & (XR078193.2) & 5'-CGAGGAATCGGAGGAAGCTTAT-3' \\
\hline Cytochrome p450 (CYP) & 5'-TGCAAGCAGTGGTGAAAGAGAC-3' & Pyrroline-5-carboxylate synthase (P5CS) & 5'-AGCCAATGCACTGGAAACAAAT-3' \\
\hline (CAB85635.1) & 5'-GACCTATAGCCCATGCGTTCAC-3' & (AJ005686.1) & 5'-CAGGCTTTAGAACCAGCCTTGA-3' \\
\hline Dehydrinl (DHNl) & 5'-GGGAGAAGGAAGAAAGGGATGA-3' & Regulator of cellular molecules (14-3-3) & 5'-TCAGGATATTGCAAACGCAGAA-3' \\
\hline$(\mathrm{JF} 896552.1)$ & 5'-GTACTTGTGGCGCTGGTATGC-3' & (FJ824803.1) & 5'-AAATGCCTGTTTCGCAAGGTTA-3' \\
\hline Dihydroflavonol-4-reductase ( $D F R)$ & 5'-TGTCTCCAAGACACTGGCTGAG-3' & Sirtuin (SIRT) & 5'-TGATGGCCTCCATCTTCGTT-3' \\
\hline (JQ308621.1) & 5'-TCGGGGAAAGAGCAGTTATGAG-3' & $(\mathrm{JN} 252254.1)$ & 5'-CACCTCAAAATCCCGCAAGT-3' \\
\hline Draught induced protein (R1G1A) (DIP) & 5'-CGTCGGTGACATGGATGAAA-3' & Small heat shock protein $(s H S P)$ & 5'-CATCTCGAGGTATGGGAACTGG-3' \\
\hline (AF503585.1) & 5'-TCCTGTTCACGGAAGCCAAT-3' & (XM003634002.1) & 5'-GTGTTCTGCTCCACGCTTACCT-3' \\
\hline Endo-B-glucanase precursor $(G l u)$ & 5'-GGGGTTATTTGGATCCCATCAT-3' & Stilbene (STSY) & 5'-GGTGCCATTGCAGGAAACTTAC-3' \\
\hline (AB601116.1) & 5'-CAGAAGCGGCGACTTATTGTCT-3' & $(\mathrm{X} 76892.1)$ & 5'-CAAGTGGGTCAAAAGCCTGAGT-3' \\
\hline Flavonol synthase (FLS) & 5'-TGCTGAGCAATGGGAAGTACAA-3' & Temperature induced lipocalin (TIL) & 5'-TCAACGAGACTTGGAGTGATGG-3' \\
\hline (XM002285805.1) & 5'-GAGGTCCGATCATTGCCTTATG-3' & (DQ222993.1) & 5'AACAGGGATAATGGGGAGGAAA-3' \\
\hline Glutathione peroxidase $(G P X)$ & 5'-GAGCACAGGAACCTGGGAGTAA-3' & Thaumatin-like protein $(T L P)$ & 5'-TTCGCACTTAACCAATTCAGCA-3' \\
\hline (XM003631370.1) & 5'-AGCACTATCGCCATTCACATCA-3' & (XM002282928.2) & 5'-TGCACCCATTGGAAGTAGGATT-3' \\
\hline Glutathion-S-transferase (GST) & 5'-TATAATGTGTGGGCAGCAAACG-3' & Tonoplast intrinsic protein $(T I P)$ & 5'-GGCACCCTAATTTTTGTGTTCG-3' \\
\hline (AY156048) & 5'-CCAATGTCCAGAAAACCCAAAG-3' & (XM003632211.1) & 5'-ACACTGCCACAAACAGTCCAAG-3' \\
\hline Glycerol-3-phosphate acyltransferase (GPAT) & 5'-GAAGCTTCAGCAGGGTCACAAT-3' & WRKY transcription facter 10 (WRKY10) & 5'-CAGGTGTTCAGTTGATGGATGC-3' \\
\hline (XM002276065.1) & 5'-GCTGGGTCTGCTTCTGTTTGAT-3' & (XM002279371.2) & 5'-AAGGGCTTTCGTGGTTATGGAT-3' \\
\hline Hypersensitive induced response protein $(H I R)$ & 5'-TGCATCCTCAAAGGCTTCGT-3' & B-actin & 5'-ACGAGAAATCGTGAGGGATG-3' \\
\hline (AY159555.1) & 5'-TGCTGTCTCAGCCTGAAGGA-3' & (AB372563.1) & 5'-ATTCTGCCTTTGCAATCCAC-3' \\
\hline
\end{tabular}


$(L O X)$, polygalacturonase-inhibiting protein $(P G I P)$, and WRKY transcription factor 10 (WRKY10) increased considerably in response to low temperature at $24 \mathrm{~h}$ after treatment. Various genes related with defense-response and cold acclimation were up-regulated in cold-treated grapevines. In 'MBA', $C L P$ and glutathione $S$-transferase (GST) were highly up-regulated by low temperature $24 \mathrm{~h}$ after treatment (Fig. 1). The expression of cold acclimationspecific protein (CAS15A), DIP, LOX and PGIP increased in response to low temperature treatment for $12 \mathrm{~h}$ when compared with untreated controls in 'MBA' (Fig. 2).

However, all genes which were up-regulated by low temperature in 'Campbell Early' showed decreases in gene expression values in 'MBA'. The greatest decreases were observed in PR4a and stilbene synthase (SYST) gene expression in 'MBA' grapevines treated with low temperature (Fig. 3). The expression of genes related with defense responses such as PR-proteins decreased in grapevines treated with low-temperature.

Among the screened genes, those encoding CAS15A, cold induced protein (CIP), glutathione $S$-transferase (GST), hypersensitive induced response protein $(H I R)$, and late embryogenesis abundant protein ( $L E A)$, were up-regulated, while genes encoding cinnamyl alcohol dehydrogenase2 (CAD2) and cold acclimation protein (WCS120) were down-regulated by low temperature treatment in both 'Campbell Early' and 'MBA'.

The Venn diagram (Fig. 4) presents the distribution of significantly induced gene expression patterns in response to the low-temperature treatment in both 'Campbell Early'
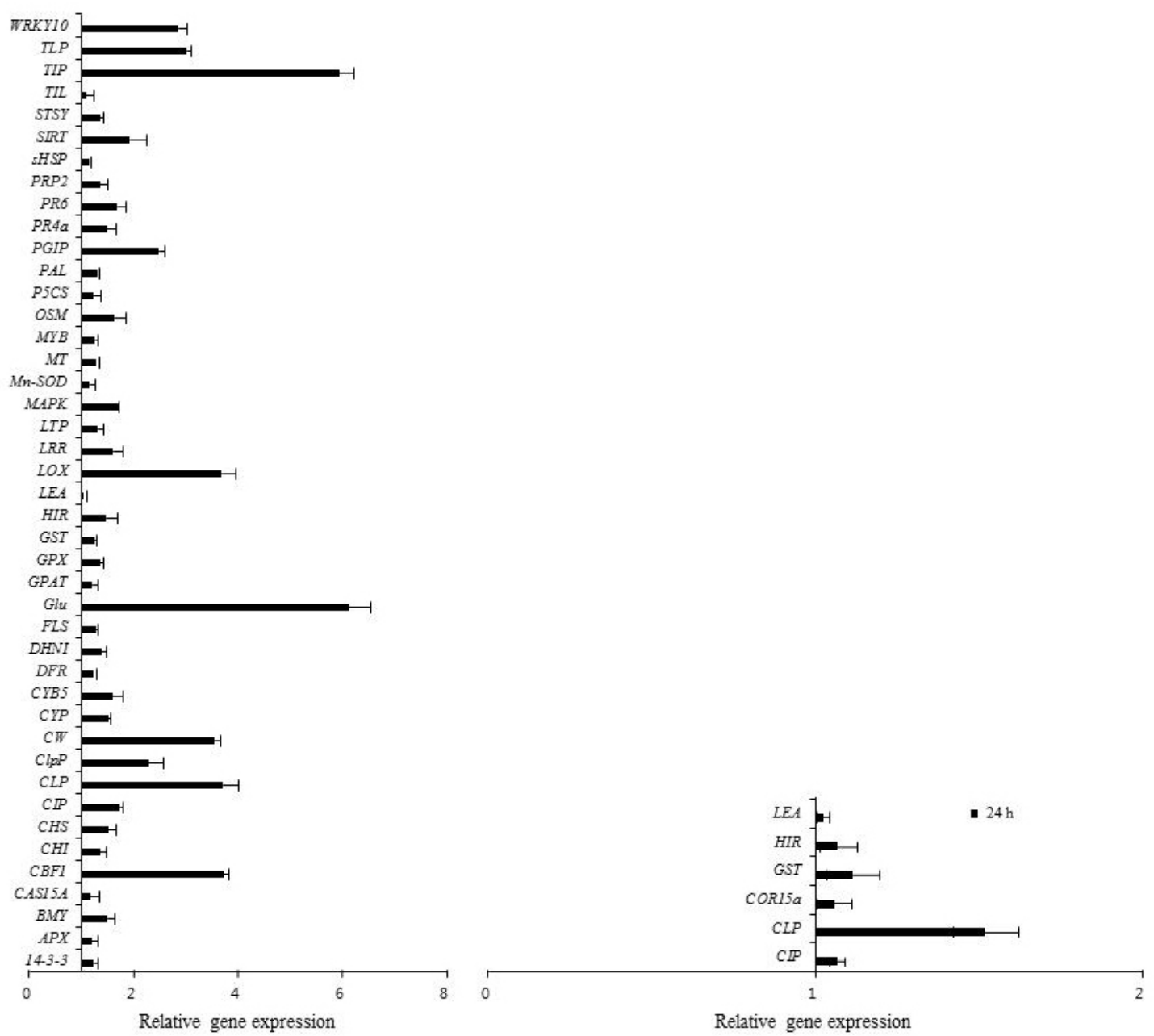

Fig. 1. Quantitative real-time PCR analysis of up-regulated gene expression in 'Campbell Early' (left) and 'MBA' (right) in response to low temperature. Each bar indicates the SEs $(n=3)$. 


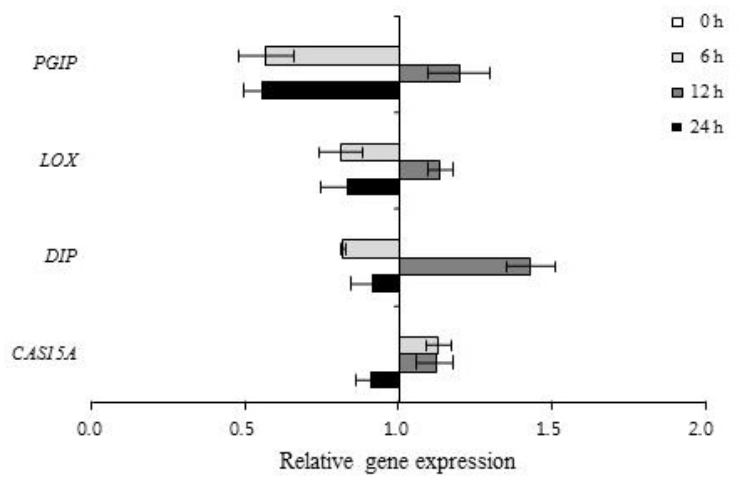

Fig. 2. Quantitative real-time PCR analysis of differential gene expression in 'Muscat Bailey A' in response to low temperature. Each bar indicates the SEs $(\mathrm{n}=3)$. and 'MBA'. Overall, 35 genes encoding ascorbate peroxidase $(A P X), C B F 1$, chalcone synthesis related ( $C H S$ and $C H I)$, $C l p P, C W$, cytochrome B5 (CYB5), Glu, glycerol-3-phosphate acyltransferase (GPAT), leucine rich repeat (LRR), lipid transfer protein (LTP), O-methyltransferase (MT), MYB transcription factor $(M Y B)$, phenylalanine ammonia lyase $(P A L)$, pathogen related proteins ( $P R 4 a$ and $P R O)$, small heat shock protein (sHSP), SIRT, STSY, TIP, TLP, WRKY10, and regulator of cellular molecules (14-3-3) were upregulated in 'Campbell Early' and down-regulated in 'MBA' in response to low-temperature treatment. These changes in gene expression showed that defense responserelated genes for cold acclimation were induced and wheat

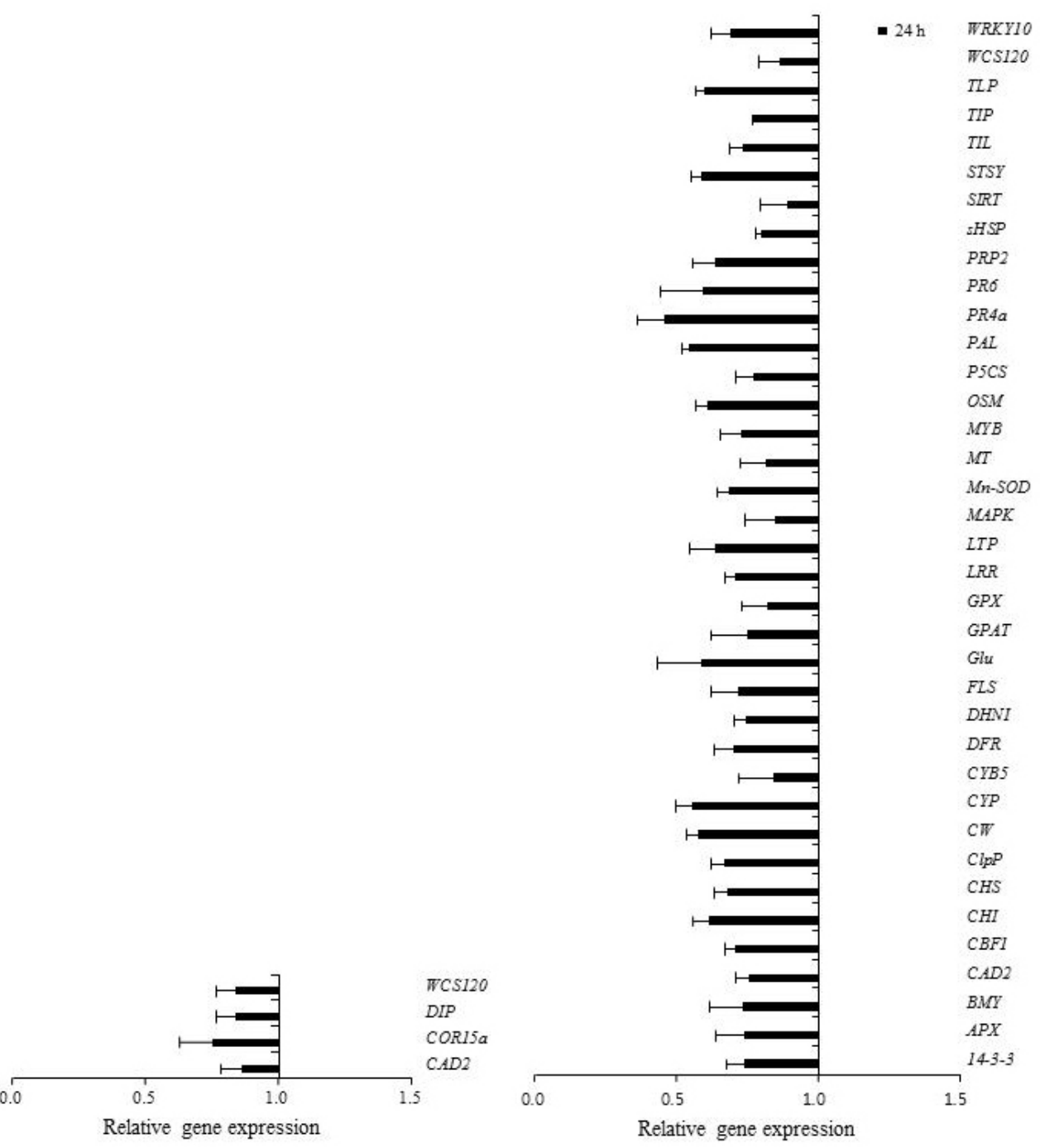

Fig. 3. Quantitative real-time PCR analysis of down-regulated gene expression in 'Campbell Early' (left) and 'Muscat Bailey $A^{\prime}$ (right) in response to low temperature. Each bar indicates the SEs $(n=3)$. 


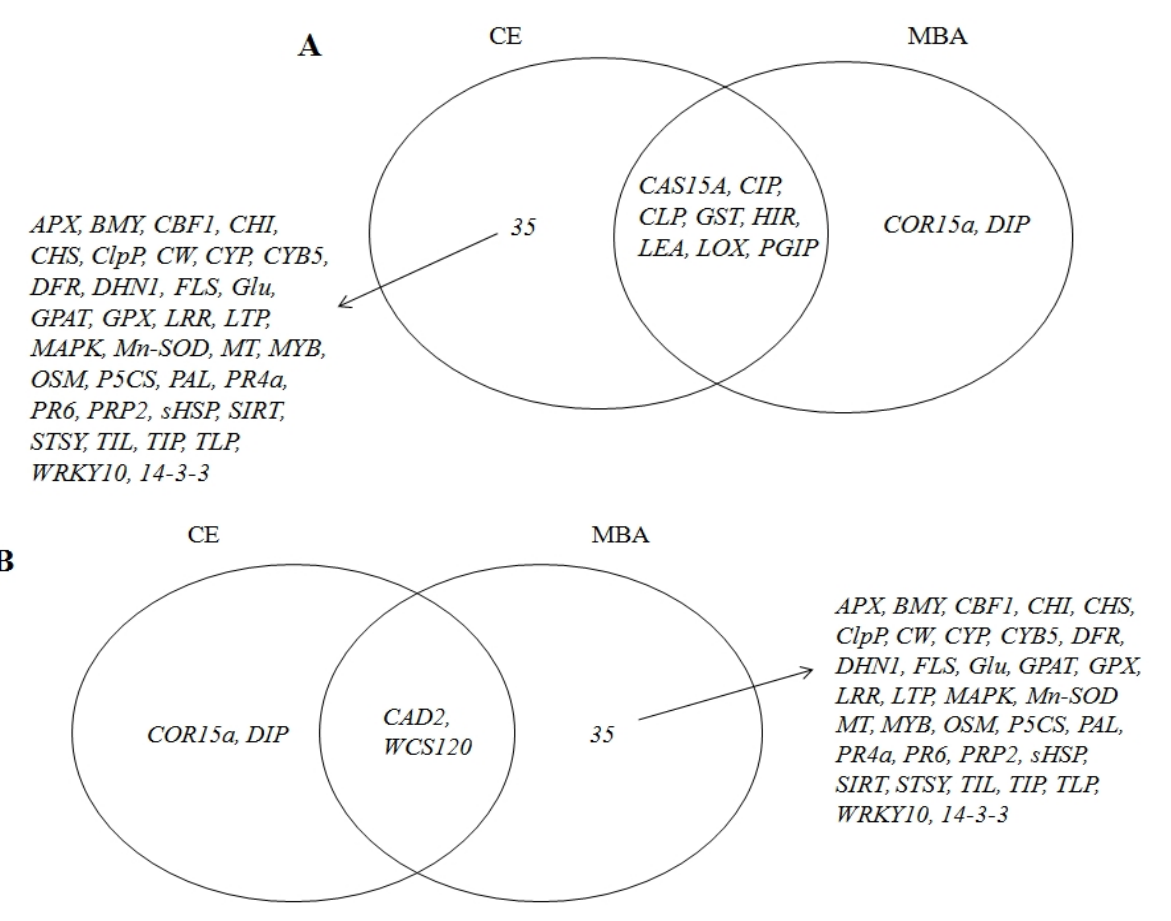

Fig. 4. Venn diagrams of differentially expressed genes in dormant buds of 'Campbell Early' and 'Muscat Bailey A' grapevines in response to low temperature. A, up-regulated genes; B, down-regulated genes.

cold-specific gene decreased in grapevines. However, DIP and cold regulated protein 15 a $(C O R 15 a)$, which were up-regulated in 'MBA', were down-regulated in 'Campbell Early' in response to low-temperature treatment. It is worth noting that the expression of the 35 genes following cold treatment differed between 'MBA' (sensitive) and 'Campbell Early' (moderately tolerant) grapevines. The differential expression of the described genes likely resulted from the difference in responses to cold and cold-acclimation capabilities. Therefore, these candidate sequences with different expression patterns in response to cold could be useful as functional molecular markers to assist in selecting cold-tolerant vines for grape breeding programs. The significant differences in the expression of the aforementioned genes were confirmed by RT-PCR. Specifically, 33 of the aforementioned genes were analyzed by RT-PCR and their expression patterns were found to be consistent with the results of real-time PCR (Fig. 5 and 6).

Low temperature affects virtually all aspects of cellular function in plants. Lipid molecules are also very important in signal transduction during cold stress (Yadav 2010). COR $15 a$ expression resulted in a decrease in the propensity of the membranes to form hexagonal II phase lipids in response to freezing (Uemura and Steponkus 1997). WCS120 protein acts as an important protective agent of many vital cellular proteins in cold-acclimated plant tissue (Houde et al. 1995; Nikolai et al. 2008; Sarhan et al. 1997). Although genes encoding the WCS120 protein were reported to be induced in wheat and barley exposed to low temperature, they showed decrease of expression in 2 grapevine cultivars treated with freezing temperature in this study. Their expression and roles in defense responses to low temperature in plants including grapevines should be studied in the near future. The relationship between $W R K Y$ and abiotic stress responses has been reported in some plant species. For example, at least 4 WRKY genes were shown to be involved in the drought, cold, or salinity responses in Arabidopsis (Seki et al. 2002).

Generally, expression of late embryogenesis abundant proteins $(L E A)$ responsible for the stabilization of membranes and proteins through detergent-like or chaperone activities (Close 1997) and heat shock proteins (HSPs) responsible for the functional conformations of the protein (Wang et al. 2004) are induced in response to different abiotic stresses 
in plants. Various stress-responsive genes were induced by drought, high-salinity, cold and ABA in the abiotic-stress signal transduction pathway systems (Ishitani et al. 1997; Xiong and Zhu 2002).

TIL gene expression was up-regulated during cold acclimation and heat-shock treatment from wheat and Arabidopsis (Charron et al. 2002). In addition, the accumulation of compatible osmolytes and antioxidants was stimulated by many factors including cold, drought, and salt stress in plants, and such changes caused by cold stress adversely

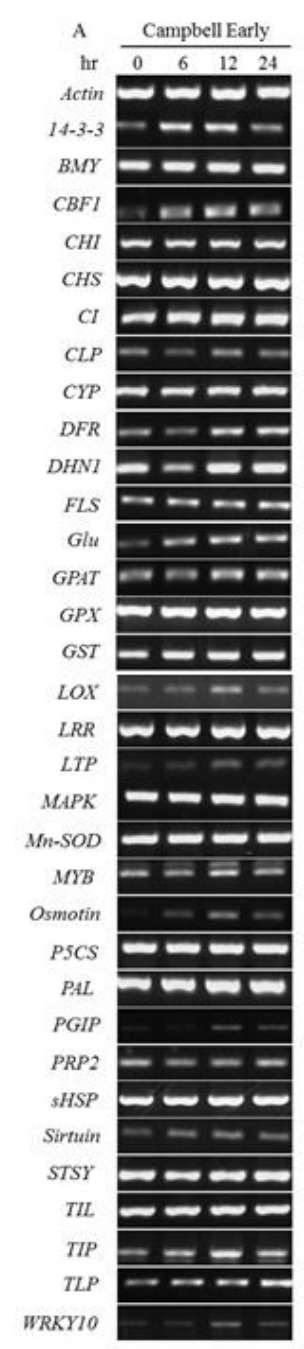

B

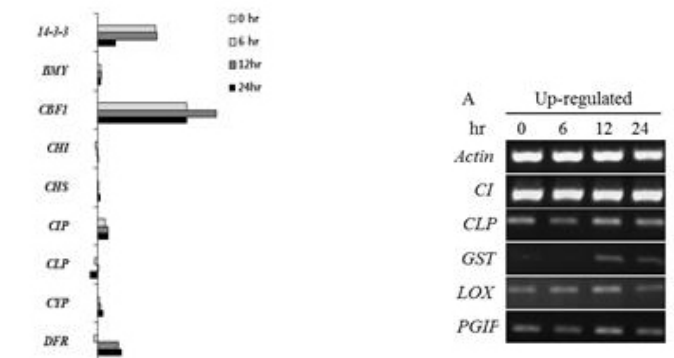

Den

ns

$a$

GPAT

GPX

Gst

$L O X$
$L R R$

LRR
LIP

LIP
MAPE

MesOD

Mns

OSW
PSCS

PSCS
PAL

$P A L$
$P G I P$

PRP2

,HSP

$S I R T$
$S T S Y$

III

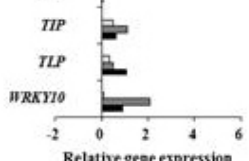

Relutive geace expression

Fig. 5. Semi-quantitative RT-PCR analysis to screen genes induced in dormant buds of 'Campbell Early' grapevines in response to low temperature. A, RTPCR gel image; B, quantitative data for gel images from ImageJ analysis. affected the growth and development of plants (Hasegawa et al. 2000).

Zhang et al. (2005) reported that transcript levels of $C H I$, which is related to anthocyanin synthesis, differed among interspecies, but were elevated to much higher levels in Poncirus rootstock during cold acclimation. $P A L$ and $C H S$ mRNAs were accumulated at similar levels in response to low temperatures (Leyva et al. 1995).

In plants, cold, drought, and salt stresses stimulated the accumulation of compatible osmolytes and antioxidants (Hasegawa et al. 2000). Xiong and Zhu (2001) reported that the signal transduction networks for cold, drought, and salt stress could be divided into three major signaling types,
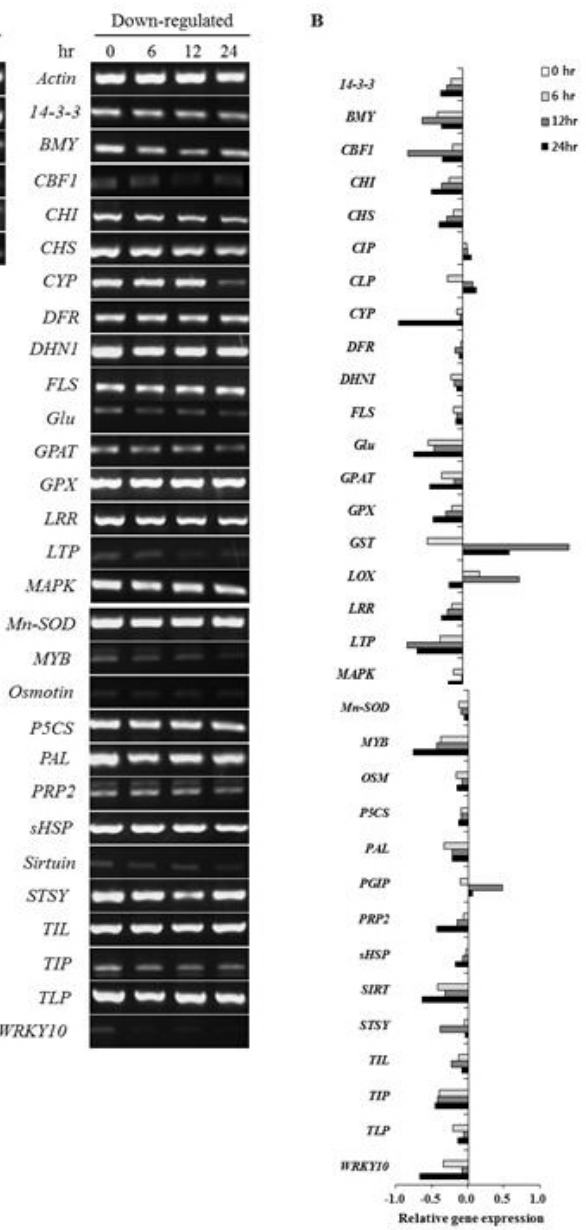

Fig. 6. Semi-quantitative RT-PCR analysis to screen genes induced in dormant buds of 'Muscat Bailey A' grapevines in response to low temperature. A, RT-PCR gel image; B, quantitative data for gel images from ImageJ analysis. 
and that among them, Type I signaling may contribute to the production of compatible osmolytes and antioxidants, and may also be related to cell cycle regulation under osmotic stress.

Dehydrin proteins have been reported to be accumulated in plants exposed to environmental stress factors such as water stress (Caruso et al. 2004) or cold stress (Caruso et al. 2004; Hara et al. 2004). In Arabidopsis, some of the cold-inducible genes encode proteins that share similarity with the response to the ABA/late embryogenesis abundant/ dehydration-induced (RAB/LEA/DHN) class of polypeptides (Gilmour et al. 1992; Guo et al. 1992; Lang and Palva 1992).

Seki et al. (2001) reported that, in Arabidopsis, induction of $\beta$-amylase occurred as early as $2 \mathrm{~h}$ after exposure to cold stress. Kaplan and Guy (2004) reported that BMY8 expression increased dramatically as early as $6 \mathrm{~h}$ and peaked at $24 \mathrm{~h}$, then decreased gradually, but remained higher under cold shock at $5^{\circ} \mathrm{C}$ than control levels at $192 \mathrm{~h}$.

The accumulation of PGIP transcripts after storage in the cold has been reported in apple (Yao et al. 1999), and cold induced the expression of AtPGIP1, but not AtPGIP2, has been observed in Arabidopsis (Ferrari et al. 2003). These findings suggested that low temperatures can increase susceptibility to diseases, and that cold induction of defensive proteins might provide protection from pathogen infections. Finally, antimicrobial proteins such as $\beta$-glucanase and chitinase, which are highly homologous with PR proteins, were accumulated in the leaf apoplast of winter rye after cold exposure (Hon et al. 1995).

Plant temperature-induced lipocalin and HSP are thought to participate in plant responses to heat and cold stress (Chi et al. 2009), but it has been suggested that they function in different protection systems. Expression of $T I L$ was induced during treatment of heat shock and cold acclimation in wheat and Arabidopsis (Charron et al. 2002). Additionally, the quantity of Arabidopsis TIL 1 was significantly increased upon cold acclimation in Arabidopsis leaf (Kawamura and Uemura 2003).

In this study, 67 genes responding to biotic or abiotic stress were selected for screening for differential expression in 'Campbell Early' and 'Muscat Bailey A' by low temperature treatment. Most of genes tested in this study showed differential expression patterns in transcription level in response to cold stress in grapevines.

Analysis of the differential expression of defense related genes in two grapevines could provide useful resources to breeding programs for development of low temperature tolerant grapevines. A number of valuable genes specifically expressed in cold tolerant grapevines should be selected through further studies such as transcriptome analysis. Sequences of genes with specific expression to low temperature could be useful in development of molecular markers based on SNP/Indels in tolerant grapevine breeding programs.

\section{ACKNOWLEDGEMENTS}

This work was supported by a grant (PJ008224) from the Agricultural R\&D Project, Rural Development Administration, Republic of Korea.

\section{REFERENCES}

Ahn SY, Kim SH, Choi SJ and Yun HK. 2012. Characteristics of cold hardiness and growth in grapevines grown in rain shelter type cultivation system in the vineyard. Kor. J. Hort. Sci. Technol. 30:626-634.

Caruso A, Morabito D, Delmotte F, Kahlem G and Carpin S. 2004. Dehydrin induction during drought and osmotic stress in Populus. Plant Physiol. Biochem. 40:1033-1042.

Charron JBF, Breton G, Badawi M and Sarhan F. 2002. Molecular and structural analyses of a novel temperature stress-induced lipocalin from wheat and Arabidopsis. FEBS Lett. 517:129-132.

Chi WT, Fung RW, Liu HC, Hsu CC and Charng YY. 2009. Temperature induced lipocalin is required for basal and acquired thermotolerance in Arabidopsis. Plant Cell Environ. 32:917-927.

Close TJ. 1997. Dehydrins: A commonality in the response of plants to dehydration and low temperature. Physiol. Plant 100:291-296.

Cook D, Fowler S, Fiehn O and Thomashow MF. 2004. A prominent role for the $\mathrm{CBF}$ cold response pathway in configuring the low temperature metabolome of Arabidopsis. Proc. Natl. Acad. Sci. (USA) 101:15243-15248. 
Ferrari S, Vairo D, Ausubel FM, Cervone F and De Lorenzo G. 2003. Tandemly duplicated arabidopsis genes that encode polygalacturonase-inhibiting proteins are regulated coordinately by different signal transduction pathways in response to fungal infection. Plant Cell 15:93-106.

Gilmour SJ, Artus NN and Thomashow MF. 1992. cDNA sequence analysis and expression of two cold-regulated genes of Arabidopsis thaliana. Plant Mol. Biol. 18:13-21.

Guo W, Ward RW and Thomashow MF. 1992. Characterization of a cold-regulated wheat gene related to Arabidopsis Cor47. Plant Physiol. 100:915-922.

Hara M, Fujinaga M and Kuboi T. 2004. Radical scavenging activity and oxidative modification of citrus dehydrin. Plant Physiol. Biochem. 42:657-662.

Hasegawa PM, Bressan RA, Zhu JK and Bohnert HJ. 2000. Plant cellular and molecular responses to high salinity. Annu. Rev. Plant Mol. Plant Physiol. 51:463-499.

Hon WC, Griffith M, Chong P and Yang DCS. 1994. Extraction and isolation of antifreeze proteins from winter rye (Secale cereale L.) leaves. Plant Physiol. 104:971-980.

Houde M, Daniel C, Lachapelle M, Allard F, Laliberte S and Sarhan F. 1995. Immunolocalization of freezing-tolerance associated proteins in the cytoplasm and nucleoplasm of wheat crown tissues. Plant J. 8:583-593.

Hughes MA and Dunn MA. 1990. The effect of temperature on plant growth and development. Biotechnol. Genet. Eng. Rev. 8:161-187.

Ishitani M, Xiong L, Stevenson B and Zhu JK. 1997. Genetic analysis of osmotic and cold stress signal transduction in Arabidopsis: interactions and convergence of abscisic acid-dependent and abscisic acid-independent pathways. Plant Cell 9:1935-1949.

Kaplan F and Guy CL. 2004. ß-Amylase induction and the protective role of maltose during temperature shock. Plant Physiol. 135:1674-1684.

Kawamura Y and Uemura M. 2003. Mass spectrometric approach for identifying putative plasma membrane proteins of Arabidopsis leaves associated with cold acclimation. Plant J. 36:141-154.

Kotak S, Larkindale J, Lee U, von Koskull-Doring P, Vierling E and Scharf KD. 2007. Complexity of the heat stress response in plants. Curr. Opin. Plant Biol. 10:310-316.

Lang V and Palva ET. 1992. The expression of a rab-related gene, rab18, is induced by abscisic acid during the cold acclimation process of Arabidopsis thaliana (L.) Heynh. Plant Mol. Biol. 20:951-962.

Larkindale J, Hall JD, Knight MR and Vierling E. 2005. Heat stress phenotypes of Arabidopsis mutants implicate multiple signaling pathways in the acquisition of thermotolerance. Plant Physiol. 138:882-888.

Leyva A, Jarillo JA, Salinas J and Martinez-Zapater JM. 1995. Low temperature induces the accumulation of phenylalanine ammonialyase and chalcone synthase mRNAs of Arabidopsis thaliana in a light-dependent manner. Plant Physiol. 108:39-46.

Monroy AF and Dhindsa RS. 1995. Low-temperature signal transduction - Induction of cold acclimation-specific genes of alfalfa by calcium at 25C. Plant Cell 7:321-331.

Monroy AF, Sarhan F and Dhindsa RS. 1993. Cold- induced changes in freezing tolerance, protein-phosphorylation, and gene-expression - Evidence for a role of calcium. Plant Physiol. 102:1227-1235.

Nikolai KC, Ryozo I and Yaroslav B. 2008. Differential expression of two winter wheat alpha-tubulin genes during cold acclimation. Cell Biol. Int. 32:574-578.

Sanghera GS, Wani SH, Hussain W and Singh NB. 2011. Engineering cold stress tolerance in crop plants. Curr. Genomics 12:30-43.

Sarhan F, Ouellet F and Vazquez-Tello A. 1997. The wheat wcs 120 gene family. A useful model to understand the molecular genetics of freezing tolerance in cereals. Physiol. Plant. 101:439-445.

Seki M, Narusaka M, Abe H, Kasuga M, YamaguchiShinozaki K, Carninci P, Hayashizaki Y and Shinozaki K. 2001. Monitoring the expression pattern of 1300 Arabidopsis genes under drought and cold stresses by using a fulllength cDNA microarray. Plant Cell 13:61-72.

Seki M, Narusaka M, Ishida J, Nanjo T, Fujita M, Oono Y, Kamiya A, Nakajima M, Enju A, Sakurai T, Satou M, Akiyama K, Taji T, Yamaguchi-Shinozaki K, Carninci P, Kawai J, Hayashizaki Y and Shinozaki K. 2002. Monitoring the expression profiles of 7000 Arabidopsis genes under drought, cold and high salinity stresses using a full-length cDNA microarray. Plant J. 31:279-292.

Sreekantan L, Mathiason K, Grimplet J, Schlauch K, Dickerson JA and Fennell AY. 2010. Differential floral development and gene expression in grapevines during long and short photoperiods suggests a role for floral genes in dormancy transitioning. Plant Mol. Biol. 73: 191-205. 
Thomashow MF. 1999. Plant cold acclimation: freezing tolerance genes and regulatory mechanisms. Annu. Rev. Plant Physiol. 50:571-599.

Uemura M and Steponkus PL. 1997. Effect of cold acclimation on membrane lipid composition and freeze induced membrane destabilization, p. 171-179. In: P. Li (Ed.). Plant Cold Hardiness, Molecular Biology, Biochemistry and Physiology. Plenum Publishing Corp. New York.

Wang W, Vinocur B, Shoseyov BO and Altman A. 2004. Role of plant heat-shock proteins and molecular chaperones in the abiotic stress response. Trends Plant Sci. 9:244-252.

Wu J, Zhang Y, Zhang H, Huang H, Folta KM and Lu J. 2010. Whole genome wide expression profiles of Vitis amurensis grape responding to downy mildew by using Solexa sequencing technology. BMC Plant Biol. 10:234.

Xiong L and Zhu J. 2001. Abiotic stress signal transduction in plants: Molecular and genetic perspectives. Physiol. Plant 112:152-166.

Yadav SK. 2010. Cold stress tolerance mechanisms in plants.
Agron. Sustain. Dev. 30:515-527.

Yang G, Zhou R, Tang T and Shi S. 2008. Simple and efficient isolation of high-quality total RNA from Hibiscus tiliaceus, a mangrove associate and its relatives. Prep. Biochem. Biotechnol. 38:257-264.

Yao CL, Conway WS, Ren RH, Smith D, Ross GS and Sams CE. 1999. Gene encoding polygalacturonase inhibitor in apple fruit is developmentally regulated and activated by wounding and fungal infection. Plant Mol. Biol. 39: 1231-1241.

Zhang CK, Lang P, Dane F, Ebel RC, Singh NK, Locy RD and Dozier WA. 2005. Cold acclimation induced genes of trifoliate orange (Poncirus trifoliata). Plant Cell Rep. 23:764-749.

Zhu J, Dong CH and Zhu JK. 2007. Interplay between coldresponsive gene regulation, metabolism and RNA processing during plant cold acclimation. Curr. Opin. Plant Biol. 10: 290-295. 